\title{
"Archivos de la memoria", por Ana María Barrenechea (comp.)
}

Beatriz Viterbo, Rosario, 2003.

Reseña: Oscar Vallejos: "La literatura será siempre

el otro archivo".

¿Qué lugar ocupa la memoria en nuestras vidas? ¿Por qué parece que la memoria necesita de tecnologías para hacerse viable y quizá posible? Hay algo curioso en el modo en que estos problemas se inscriben tanto en el modo en que vivimos (experimentamos) esta época, este tiempo, este período como en el modo en que lo pensamos o intentamos conocerlo. Pertenecemos a un periodo donde el problema de la memoria y sus tecnologías traman nuestra compleja identidad.

Paolo Rossi en su libro Clavis Universalis. El arte de la memoria y la lógica combinatoria de Lulio a Leibniz plantea que lo que se llamó ars memorativa es un "fósil intelectual". Estas técnicas o artes de la memoria "artificial" ocuparon un lugar de peso dentro de la producción libresca desde el primer Renacimiento hasta la época de Leibniz; luego, estas técnicas de la memoria artificial convergieron en las enciclopedias, en las clasificaciones y en los métodos del siglo XVII. Leo en este proceso una vez más el complejo proceso que hizo pasar las habilidades humanas más notables o necesarias del cuerpo a ciertos artefactos. Mientras las ars memorativa son una ayuda (o suplemento) para mejorar una habilidad corporal o, incluso, anatómica; las enciclopedias, los grandes sistemas de clasificación y el sistema de publicaciones reemplazan la memoria (corporal: aquella que sólo se manifiesta en la presencia del cuerpo). Se constituyen los artefactos de la memoria que permiten mover conocimientos y experiencias de un lugar a otro y, como todo artefacto, ponen la memoria a disposición de muchos (casi sin tiempo y sin lugar): básicamente a disposición de quienes puedan pagarla. Una línea crítica de las tecnologías (o de los artefactos) suele llamar la atención acerca de cómo se maravilló occidente por esta posibilidad: una gramática de la producción (de tecnología) hace que nuestros modos de vinculación con el mundo (y con nosotros mismos) se vuelva básicamente tecnológica. En una misma línea crítica, se muestra que después de la segunda gran guerra y la puesta en marcha de los campos de exterminio, occidente se desencanta de la tecnología y empieza una historia de convivencia ambigua con ella. En este contexto se reedita el tema de la memoria, pero con un matiz y una esperanza diferente. La memoria como antídoto contra el mal. Este nuevo escenario genera una de las mayores ambivalencias del presente: volver a encarnar en la subjetividad la memoria -como el último, algunos dicen el único- reservorio (archivo) mientras esta sociedad produce las tecnologías informáticas: las tecnologías de la memoria más potentes que jamás hayan existido. Por un lado hay una esperanza de anclar la memoria (encarnarla) en el cuerpo pero por otro somos cada vez más conscientes de la más terrible de las enfermedades de la memoria. Esta ambivalencia enfrenta nuestra memoria con la más precisa y exitosa tecnología de la memoria. 
Estas ambivalencias estructuran nuestro espacio de vida y pensamiento en tanto, como muestra Huyssen, el problema de la memoria (y del archivo) se ha globalizado.

El libro compilado por Ana María Barrenechea que reseñamos se inscribe en esta corriente de estudiosos de la cultura que, siguiendo una frase de Barrenechea, parece consistir en estudiar objetos, instrumentos, redes de su agrupación y funcionamiento (oral-escrito, individual-colectivo, espacial-temporal, recordado-modificado-borrado) donde el problema de la memoria se opere explícitamente o que bajo esta cuña interpretativa puedan decir su funcionamiento.

Los artículos que componen el libro abordan problemas, objetos y relaciones muy diversos. Para resolver esta trama del libro, optaré por una mirada rápida que muestre los distintos problemas analizados. Jorge Panesi analiza el texto Villa de Luis Guzmán. El artículo es complejo, hecho de distintos movimientos. En uno de ellos habla de una "matriz deleuziana" y, en verdad, es un movimiento doble; uno donde se hace visible uno de los problemas a los que nos referíamos más arriba: la idea del mundo como máquina. Esta concepción estaría desplazando el problema -una conjetura de organización del mundo literario que me gustaría poder formular con más precisión- de la máquina de narrar (o del arte o técnica de narrar) a la narración del mundo. En este desplazamiento, parece acontecer eso que Panesi llama "una producción". Hay una pregunta que parece central en este artículo: "¿cómo es que un mundo novelístico, el de Guzmán, se encuentra con la historia, con la realidad histórica vivida?, ¿qué cede, qué toma y qué transforma en ese encuentro?" (p.15) Ese modo de referir a la intriga fundamental de los historiadores, de los cientistas sociales y de los críticos literarios: qué tipo de encuentro se produce allí donde la literatura se encarga de la memoria. Panesi plantea en algún momento el problema de "enfermar la memoria", ésta es una clave importante. Después de Funes, sabemos de la memoria enferma. Aquí se cifra la esperanza de Panesi: en que "la literatura sea siempre ese otro archivo" (p. 24).

Alejandra Alí lee textos de Ricardo Piglia. Alí justamente escribe del modo en que Panesi muestra como típico: la idea de "máquina" narrativa y asocia a esta máquina la idea de archivo. Como si la máquina de narrar fuera archivo. Se menciona en este artículo el gran problema de la memoria: la memoria falsa. Alí plantea que el tema de la historia le permite a Piglia plasmar reconocimiento de la "falsa memoria" pero no se vuelve una perspectiva desde la que leer esos textos. Valeria Añon, lee la Historia verdadera de la conquista de la Nueva España de Bernal Díaz del Castillo en la clave que aporta el problema de la memoria. Aparece en este texto otro de los temas recurrentes en los estudios culturales de los últimos años: el problema del otro. Estas dos coordenadas muestran al texto de Bernal tensionado por esas dos obsesiones.

Susana Artal estudia a Rabelais y presenta el problema central de la relación entre memoria y educación. Es un tópico bien conocido que la educación se sostiene sobre la memoria, ahora bien: ¿se confunde con ella? Artal muestra, entre otros aspectos, el modo en que Rabelais se compromete con una visión crítica de la memoria: del aprendizaje de memoria como opuesto a un aprendizaje que tuviera que ver con la vida. La memoria como una "acumulación azarosa de fragmentos de conocimiento, privados de significado" (p. 58) suele ser un peligro constante. Esta manera de leer a Rabelais hace que el texto enuncie de otros modos los problemas centrales de su (y nuestro) tiempo.

Paola Cortés analiza el "álbum Vistas y costumbres de la República Argentina Christiano Junior”. El artículo vuelve problemático el modo en que la fotografía interpela al presente en tanto memoria visual en una dimensión doble, la política y 
la estética. Raúl Illescas tematiza el problema de la memoria de la migración europea en los años de conformación del Estado argentino. Pero la memoria se articula a partir de los manuales, diccionarios y vocabularios que se pensaron desde el Estado para tratar con esta población nueva. El Vocabulario Argentino de Diego Díaz Salazar es el texto elegido por Illescas para analizar el modo en que fue pensado el proceso inmigratorio desde uno de sus puntos más sensibles: la articulación de la lengua. Lucila Pagliai escribe sobre el texto bilingüe sefaradí-castellano de Juan Gelman donde el problema de la memoria es una lengua que reverbera (palimpsesto) en la otra: dibaxu es el término que la autora elige para hacer visible su hipótesis de lectura. María Palleiro tematiza el problema de la memoria en la oralidad de los relatos folklóricos. La hipótesis que esboza es que los relatos orales funcionan como un sistema de recuerdo colectivo por su articulación textual y su dinamismo.

Además de la Introducción, Ana María Barrenechea escribe "Tiempo, identidad, memoria y sueño en Borges". El texto recorre el modo en que la autora articula estos términos (conceptos) para dar cuenta de cómo se presenta el problema de la memoria en Borges. Como siempre, Barrenechea muestra los caminos secretos entre los textos diversos que forman la obra de Borges.

El libro reseñado es una pieza característica del modo de producción de conocimiento en las humanidades y en ciencias sociales en nuestro país. Sobre unidades temáticas comunes se articulan distintos intereses. Lo que no da como resultado una obra común de largo aliento, sino una obra compleja con algunos nudos comunes que disipan el problema a regiones no siempre previsibles. 